its volume determined. Tests of the efficiency of the method, using synthetic mixtures of $\mathrm{BF}_{3}$ and $\mathrm{SiF}_{4}$ in proportions $2: 1$, showed that recovery of the silicon tetrafluoride was always more than 99 per cent complete. From these results it was estimated that $\mathbf{0 . 2}$ per cent of impurity could be detected in 200 c.c. of boron trifluoride using this particular apparatus, which was not specifically designed for this purpose and had an unnecessarily high internal surface volume ratio.

The use of trimethylamine as a condensing agent for the boron trifluoride, which was first tried, was found to be impracticable owing to the formation of a double compound with silicon tetrafluoride which has not previously been reported. It is characterized by the following procedure.

30.3 c.c. of silicon tetrafluoride which had been freed from hydrogen chloride by careful fractional distillation in vacuo at $-150^{\circ}$, together with $80 \cdot 8$ c.c. of trimethylamine dried by passage over phosphorus pentoxide, were condensed in a trap cooled by liquid nitrogen. On permitting the mixture to warm up and volatilize, a cloud of white solid was produced, and analysis of the gas remaining revealed that this consisted of $49 \cdot 1$ c.c. excess trimethylamine. The gaseous reactants had thus combined in the volume ratio $\mathrm{NM}_{3} / \mathrm{SiF}_{4}=1.04$. A later experiment using an excess of silicon tetrafluoride gave a volume ratio $\mathrm{NM}_{3} / \mathrm{SiF}_{4}=1 \cdot 01$. It therefore appeared that these two gases had formed an equimolecular double compound, which proved to have a dissociation pressure of about $45 \mathrm{~mm}$. at room temperature, and $0.1 \mathrm{~mm}$. at $-78^{\circ} \mathrm{C}$.

University of Edinburgh, Late of National Research Council, Atomic Energy Division, Chalk River, Ont. Oct. 25.

${ }^{1}$ Seel, Z. anorg. Chem., 250, 331 (1943)

${ }^{2}$ Nesmejaow and Kahn, Ber., 67, 372 (1934).

\section{N. MiLleR}

abandoned if the assumed extension of the sun is untenable.

Ranmore,

W. F. SEDGWICK

Highdown Road,

London, S.W.15.

\section{'Velsicol 1068'}

Kearns, Ingle and Metcalf ${ }^{1}$ have recently commented on the properties of a chlorinated hydrocarbon of empirical formula $\mathrm{C}_{10} \mathrm{H}_{6} \mathrm{Cl}_{8}$ which was described as "possibly a mixture of isomers which as yet have not been resolved and evaluated individually". In a note $e^{2}$ on this new insecticide it has been stated that in solubility the compound, to which the trade name 'Velsicol 1068' has been assigned, resembles D.D.T. and benzenehexachloride. It seems desirable to direct attention to the fact that unlike the two latter compounds, we have confirmed the observation of Kearns and co-workers ${ }^{1}$ that the new compound is soluble in all proportions in most organic solvents, including deodorized kerosene. This property is of considerable importance in formulating products for test purposes. It appears that apart from the results of Kearns and co-workers ${ }^{1}$ little has been published on the insecticidal efficacy of 1068 , but these workers presented results to support their statement that "(1068) was found to be more toxic than D.D.T. and to compare favourably in toxicity to the pure $\gamma$ isomer of benzenehexachloride"s.

\section{Checking of Sir James Jeans' Numerical Calculations}

IN the preface to his "Introduction to the Kinetic Theory of Gases", 1940, the late Sir James Jeans intimates that I had checked "all the numerical calculations" in the fourth edition (1925) of his "Dynamical Theory of Gases". It should, however, be stated that as a rule I only checked one or two of the items in the tables. As regards these and the numerical results given in the text, I did indeed as a rule agree, at least approximately, with Jeans' figures; but in a few cases, some of which are to be mentioned in a forthcoming note in the Philosophical Magazine, my results differed substantially.

Another quite distinct point is that, in the third edition (1933) of his book "The Universe Around Us", Sir James Jeans credits me on page 254 with a theory of the tidal origin of the planets which may seem to adumbrate his own theory. But whereas I did in effect suggest that the outermost planet might have been produced by the tidal action of a passing star on the nebulous sun, assumed to extend to the planet's orbit, I supposed that the remaining planets were each produced in succession by the tidal action of the nearest existing planet on the contracting solar body. This supposition must, however, be

\author{
Hygienic Chemical Co., Ltd., \\ 600 Commercial Road, \\ London, E.14. \\ Nov. 19. \\ ${ }^{1}$ Kearns, C. W., Ingle, L., and Metcalf, R. L., J. Econ. Ent, 38, 661 \\ (1945). \\ 2 Nature, 158, 701 (1946). \\ 3 Taylor, E. L., Nature, 155, 85 (1945).

\section{T. F. WEST}

\section{A Revival of Natural Oyster Beds}

IN Nature of October 26, p. 586, Dr. P. Korringa has discussed the problem of reviving natural oyster beds. In general, I agree with his views; but I should like to add some comments on the origin of the oysters used when trying to revive a depleted bed.

In the south-eastern part of Norway, we often have great mortality among oysters reared in netting trays. This mortality, however, only affects oysters taken as spat from districts with different hydrographical conditions. Oysters from spat spawned in the same waters have never failed. When we first noticed this, we believed that the spat from other districts might have been damaged during transport. But if this was the case, the mortality should be greatest shortly after arrival. Heavy mortality can, however, take place a year or two after trans. plantation ; although in the same locality the native oysters flourish.

We are inclined to believe that oysters from the western coast of Norway are not able to stand the rather large variations in salinity occurring on the Skagerrack coast.

Flødevig Sea-fish Hatchery, Alf Dannevig 